\title{
Death in the Digital Age: A Systematic Review of Information and Communication Technologies in End-of-Life Care
}

\author{
Kirsten Ostherr, PhD, MPH, Peter Killoran, MD, MS, ${ }^{2-4}$ Ross Shegog, PhD, and Eduardo Bruera, MD ${ }^{5}$
}

\begin{abstract}
Background: End-of-life (EOL) communication plays a critical role in ensuring that patients receive care concordant with their wishes and experience high quality of life. As the baby boomer population ages, scalable models of end-of-life communication will be needed to ensure that patients receive appropriate care. Information and communication technologies (ICTs) may help address the needs of this generation; however, few resources exist to guide the use of ICTs in EOL care.

Objective: The primary objective was to identify the ICTs being used in EOL communication. The secondary objective was to compare the effectiveness of different ICTs in EOL communication.

Methods: The study was a systematic review, following Preferred Reporting Items for Systematic Reviews and Meta-Analyses (PRISMA) guidelines. We systematically searched seven databases for experimental and observational studies on EOL communication between doctors and patients using ICTs, published in 1997-2013. Results: The review identified 38 relevant articles. Eleven types of technology were identified: video, website, telephone, videoconferencing, e-mail, telemonitoring, Internet search, compact disc, fax, PalmPilot, and short message service (SMS) text messaging. ICTs were most commonly used to provide information or education, serve as decision aids, promote advance care planning (ACP), and relieve physical symptom distress.

Conclusions: The use of ICTs in EOL care is a small but growing field of research. Additional research is needed to adapt older, analog technologies for use in the digital age. Many of the interventions discussed in this review do not take full advantage of the affordances of mobile, connected health ICTs. The growing evidence base for e-health applications in related fields should guide future interventions in EOL care.
\end{abstract}

\section{Introduction}

C OMMUNICATION BETWEEN DOCTORS, patients and families plays a decisive role in ensuring that patients receive end-of-life (EOL) care concordant with their wishes. Yet effective communication between dying patients and health care providers is often lacking, ${ }^{1-7}$ resulting in unwanted intensive interventions, delayed referral to hospice, increased medical costs, feelings of regret among caregivers, and poor quality of life at EOL. ${ }^{8-25}$ Efforts to bring EOL care into accord with patients' wishes through use of advance directives (ADs) and Do Not Resuscitate orders (DNRs) have had limited success, in part because meaningful options are often offered too late, ${ }^{9,12}$ and preferences are rarely documented in the patient's medical record. ${ }^{26,27}$

\section{The role of information and communication technologies}

Programs that link documentation of EOL preferences to an electronic registry demonstrate the potential for new information and communication technologies (ICTs) to make significant improvements to EOL communication. ${ }^{28-30}$ ICTs have begun to transform advance care planning (ACP) by facilitating ease of use, storage, and retrieval of documents; ${ }^{31}$ promoting health literacy; and enabling effective use of

\footnotetext{
${ }^{1}$ Rice University, Houston, Texas.

${ }^{2}$ Department of Anesthesiology, University of Texas Medical School at Houston, Houston, Texas.

${ }^{3}$ School of Biomedical Informatics, ${ }^{4}$ School of Public Health, ${ }^{5}$ M.D. Anderson Cancer Center, University of Texas, Houston, Texas.

Accepted November 24, 2015.

(C) Kirsten Ostherr, et al., 2015; Published by Mary Ann Liebert, Inc. This Open Access article is distributed under the terms of the Creative Commons License (http://creativecommons.org/licenses/by/4.0), which permits unrestricted use, distribution, and reproduction in any medium, provided the original work is properly credited.
} 
palliative care in the EOL decision making context. ${ }^{32-34}$ E-health practices that apply ICTs to the delivery and enhancement of health care services ${ }^{35,36}$ can tailor content to match individual preferences, adapt to diverse cultural norms, and respond to contextually specific cues. ${ }^{37-39}$ These features enable greater efficacy through personalized communication, helping health professionals to reach historically underserved populations more effectively. ${ }^{40-42}$ E-health methods have also improved behavioral outcomes related to important EOL domains such as medication adherence, hospital readmissions, and independent living. ${ }^{38,43-45}$

Consumer-driven, web-based initiatives such as The Conversation Project, Engage with Grace, Five Wishes, and Death over Dinner have encouraged Americans to "have the conversation" at home, "around the kitchen table, not in the ICU" so that family members may be prepared to make decisions before a crisis arises. ${ }^{25}$ These projects further demonstrate the role that ICTs and e-health methods can play in shaping EOL communication outside of the clinical setting; however, little evidence exists of their impact on clinical decision making and patient outcomes.

With the development of new techniques for enhancing and extending doctor-patient communication in the Information Age, researchers need guidance on appropriate uses of technology in EOL care. ${ }^{48-50}$ This systematic review provides a unique and valuable contribution to the research by identifying the uses and evaluating the effects of ICTs in EOL care.

\section{Methods}

This review was conducted following the Preferred Reporting Items for Systematic Reviews and Meta-Analyses (PRISMA) guidelines. ${ }^{51} \mathrm{With}$ the assistance of a health sciences librarian, we searched the literature in seven electronic databases (Medline, PubMed, PsycINFO, Sociological Abstracts, Communication Abstracts, CINAHL, and Embase). The strategy included MeSH headings and keywords related to EOL, doctor-patient communication, and technology. The Medline search strategy can be found in supplementary Table S1. (See online supplementary Table S1 at www.liebertpub.com/jpm and at www.liebertonline.com.) Further detailed search histories are available from the corresponding author upon request.

A randomly selected sample of search results was tested for inter-rater reliability by two independent screeners (K.O. and P.K.) to ensure the validity of the inclusion and exclusion criteria, ${ }^{52}$ resulting in a Cohen's kappa of 0.94 . K.O. and P.K. independently screened each title and abstract to identify studies that met inclusion criteria, and disagreements were resolved by consensus based on full-text review.

\section{Study selection}

Inclusion criteria for this systematic review required that studies address EOL communication between doctors and patients; studies focused on removal of life support and/or organ donation that do not include the patient were excluded. The studies had to address EOL communication in patient care; studies that focused solely on training health care providers without implementing the training in a health care setting were excluded. The studies had to include an ICT in the process of communication; studies that did not include any technology were excluded. Studies had to gather quantitative data on efficacy, impact, or effectiveness; studies that were descriptive and/or solely focused on usability or feasibility were excluded. Only articles published in English between 1997, when the Institute of Medicine (IOM) landmark report was published, and 2013 were included in the final review. Only research articles from journals were included; comments, editorials, dissertations, conference proceedings, case reports, etc. were excluded. Cross-sectional, casecontrol, and cohort studies and clinical trials were included. This study did not require institutional review board approval.

\section{Data extraction}

Full texts of included articles were independently screened by K.O. and P.K. Details of included studies were extracted according to predefined categories. Procedures for coding included methods for assessing risk of bias, based on the Cochrane Collaboration's recommendation in support of using a domain-based evaluation rather than a scale or a checklist. ${ }^{52}$ The quality assessment checklist and summary scores for each included study are available in supplementary Table S2. (See online supplementary Table S2 at www .liebertpub.com/jpm and at www.liebertonline.com.)

\section{Results}

Of the initial 2248 articles identified and screened, a total of 38 articles met our inclusion criteria (see Fig. 1 for PRISMA flowchart). ${ }^{33,34,53-88}$ The study populations consisted of two primary patient groups: cancer patients $(n=15)^{34,53,54,58-62,65,69,73,80,84,85,87}$ and noncancer patients $(n=23)$. The noncancer population was subdivided by age, with $29 \%$ of the studies $33,55,56,63,64,66,68,72,78,79,81$ focused on populations aged 60 years and older $(n=11) ; 8 \%$ of the studies $^{70,82,83}$ focused on populations aged 40 and older $(n=3)$; and $24 \%$ of the studies focused on populations defined by other features, including race, ${ }^{71,86}$ primary language $^{71}$ and referral ${ }^{57,67,74-77,88}$ to palliative care or pain clinic $(n=9)$. Twenty-five ${ }^{33,34,55,56,58-72,76,78,79,82,83,86}$ of the studies were conducted in the United States; three ${ }^{77,84,85}$ in Canada; five in Europe (two ${ }^{57,80}$ in the United Kingdom, one $^{73}$ in Spain, two ${ }^{53,75}$ in The Netherlands); two ${ }^{87,88}$ in Australia; one ${ }^{81}$ in Japan; one ${ }^{54}$ in Korea; and one ${ }^{74}$ in India. All articles were published in the English language (per selection criteria). Eighteen ${ }^{34,53,61,67-71,75,78,81-88}$ were quasi-experimental, pre-post-intervention studies; seventeen $^{33,54-60,62,64-66,72,73,76,79}$ were randomized, controlled trials; two ${ }^{74,80}$ were interrupted time series studies; and one ${ }^{77}$ was a prospective cohort study.

The summary characteristics of these studies are described in Table 1. Details on the bias assessment ratings are included in supplementary Table S2. Complete details on all included studies are available in supplementary Table S3. An explanation of evidence table codes is included in supplementary Table S4. (See online supplementary Tables S2, S3, and S4 at www.liebertpub.com/jpm and at www.liebertonline.com.)

\section{Types of technology used}

Eleven types of technology were used in the included studies, with some studies employing more than one type. 


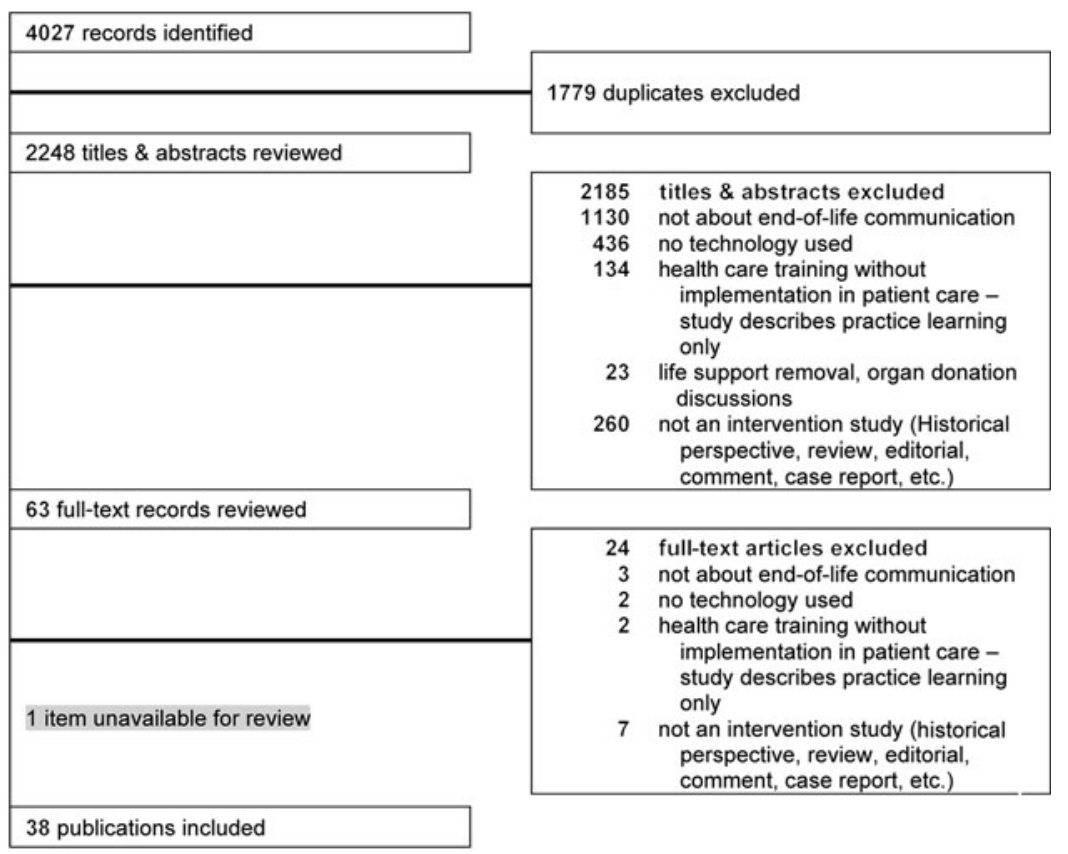

FIG. 1. PRISMA flowchart.

Of these, 55\% $(n=22)$ used video $33,34,54,56,59,62,64-66,70-72$, $75,77,79-84,86,87$ as the intervention technology; $15 \%(n=6)$ developed a prototype website $;^{58,60,67,69,73,78} 10 \%(n=4)$ used a telephone ${ }^{55,57,68,76}$ and the remaining technologiesvideoconferencing, ${ }^{85}$ e-mail prompt, ${ }^{61}$ telemonitoring, ${ }^{63}$ Internet search ${ }^{60}$ (without developing prototype website), compact disc, ${ }^{53}$ fax,${ }^{88}$ PalmPilot, ${ }^{88}$ and SMS text messaging ${ }^{74}$ - were used once each.

\section{Technology by date of study}

Research on ICTs in EOL care has grown significantly in recent years (see Fig. 2). Between 1997-2009, 16 studies $56,57,66-68,71,72,75-77,79,83,84,86-88$ that met our inclusion criteria were published in this field, averaging less than one

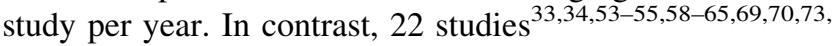
$74,78,80-82,85$ ( $58 \%$ of included studies) were published between 2010-2013, averaging five studies per year, with nine of the studies ${ }^{58-62,73,74,78,85}$ included in this review (24\%) published in 2013 alone.

\section{Purpose of technology}

Seven purposes of ICT use in EOL care were identified. The most common purposes for using technology in these interventions were to provide information/education and to serve as decision aids, followed by promoting ACP and/or documenting a patient's code status, and relieving physical symptom distress. See Figure 3 on the purposes of technology use, setting (clinic or home), and mode of interaction (remote or face-to-face).

On average, each intervention used ICTs for at least two purposes, with $61 \%$ of studies $(n=23)$ using technology to provide information/education, and $53 \%$ of studies $(n=20)$ using technology as a decision aid. Approximately $24 \%$ of the studies in this review $(n=9)$ used ICTs to relieve physical symptom distress. While this sample size is relatively small, the use of technology to enable remote interventions for managing patient pain is extremely promising for delivering improved health outcomes, quality of life, and cost savings for patients at the EOL.

\section{Discussion}

The aim of this study was to review existing studies describing the use of ICTs in EOL care for communication between doctors, patients, and family members. The results show that ICT use in EOL care is an emergent and expanding area of research, with a variety of ICT tools undergoing rigorous evaluation. Although the field is young, almost half (45\%) of the included studies were randomized, controlled trials - the gold standard in evidence-based medicine-and therefore, the evidence base for the field shows promising signs of maturation. However, many of the studies compared the effectiveness of the ICT intervention to "usual care," with fewer studies comparing effectiveness among different ICTs. Given the widespread recognition from the IOM and the research cited here that "usual care" for patients at the EOL is inadequate, this measure of comparison does not provide results that are as meaningful as they should be.

An additional feature of the relative immaturity of this field is its lack of unbiased research. For bias risk criteria, the most problematic categories were blinding of participants and personnel, allocation concealment, and blinding of outcome assessment. Many of these biases were due to the inherent limitations of small sample sizes and the use of a pre-post intervention study design with no control group. Finally, the sensitive nature of conducting research on patients nearing EOL poses both ethical and logistical challenges that require researchers to develop innovative techniques that do not always conform to the scientific gold standard of the doubleblind, randomized, controlled trial. This field of research may require ongoing development of innovative, field-specific standards for research validity as it matures. 


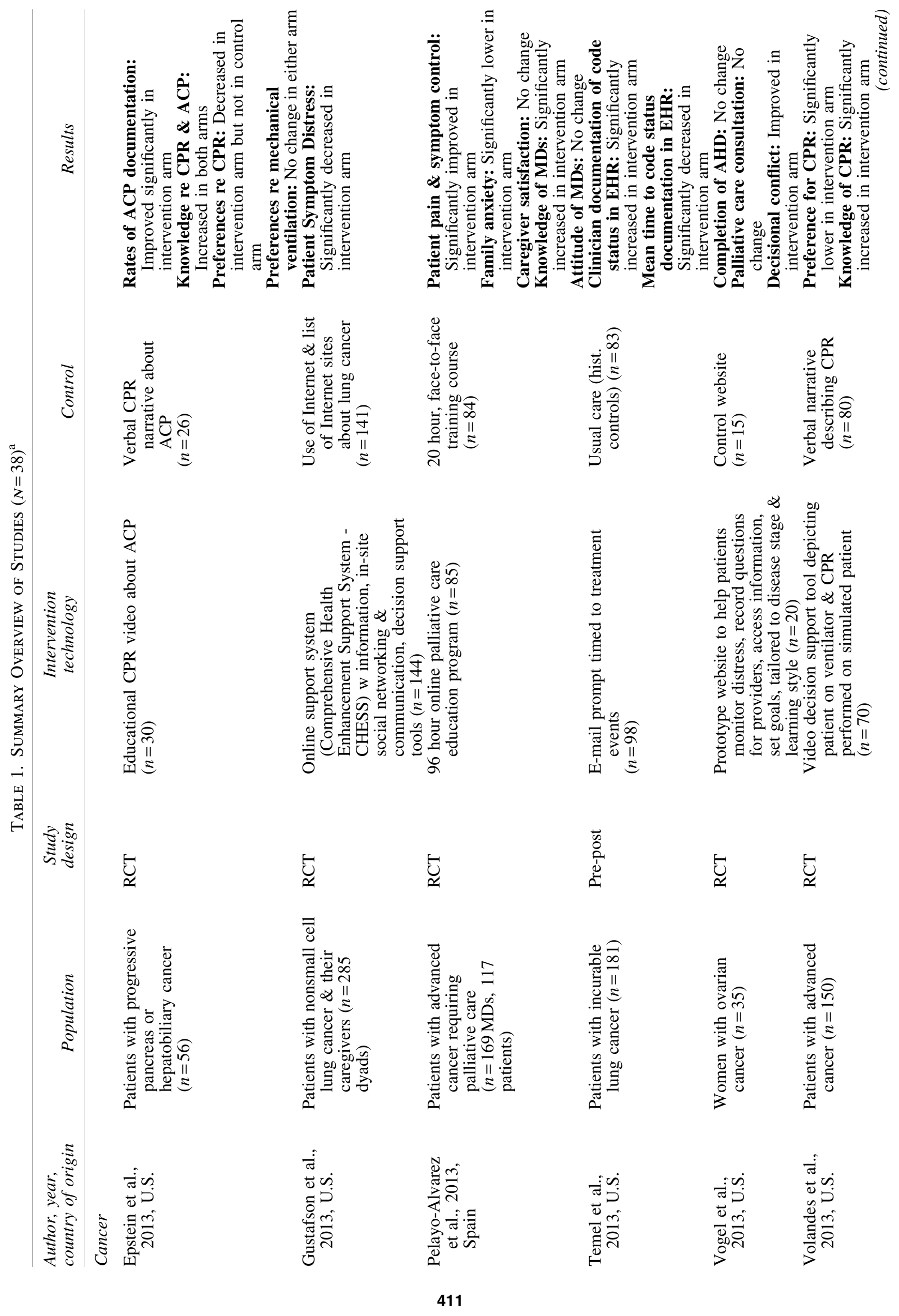




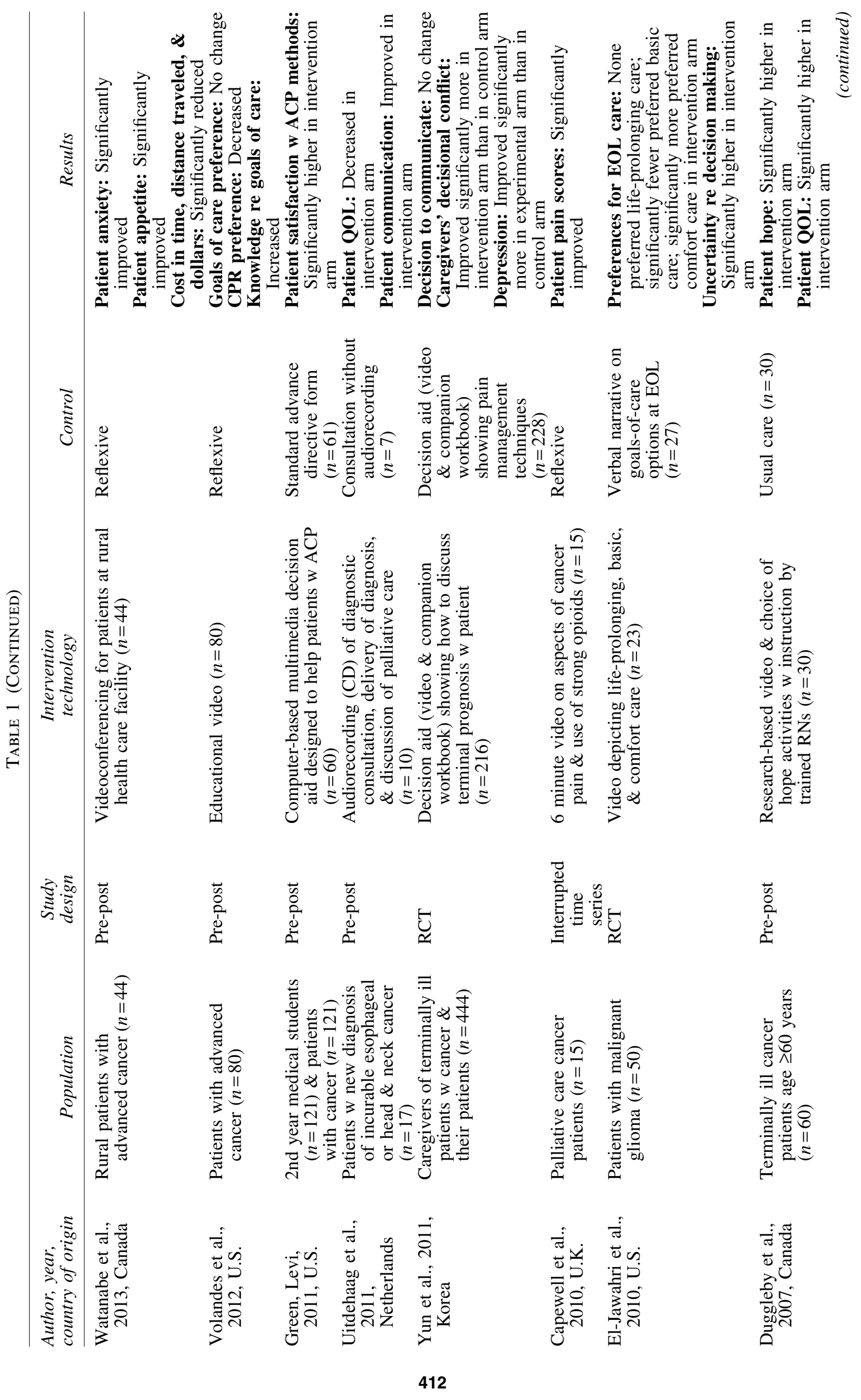




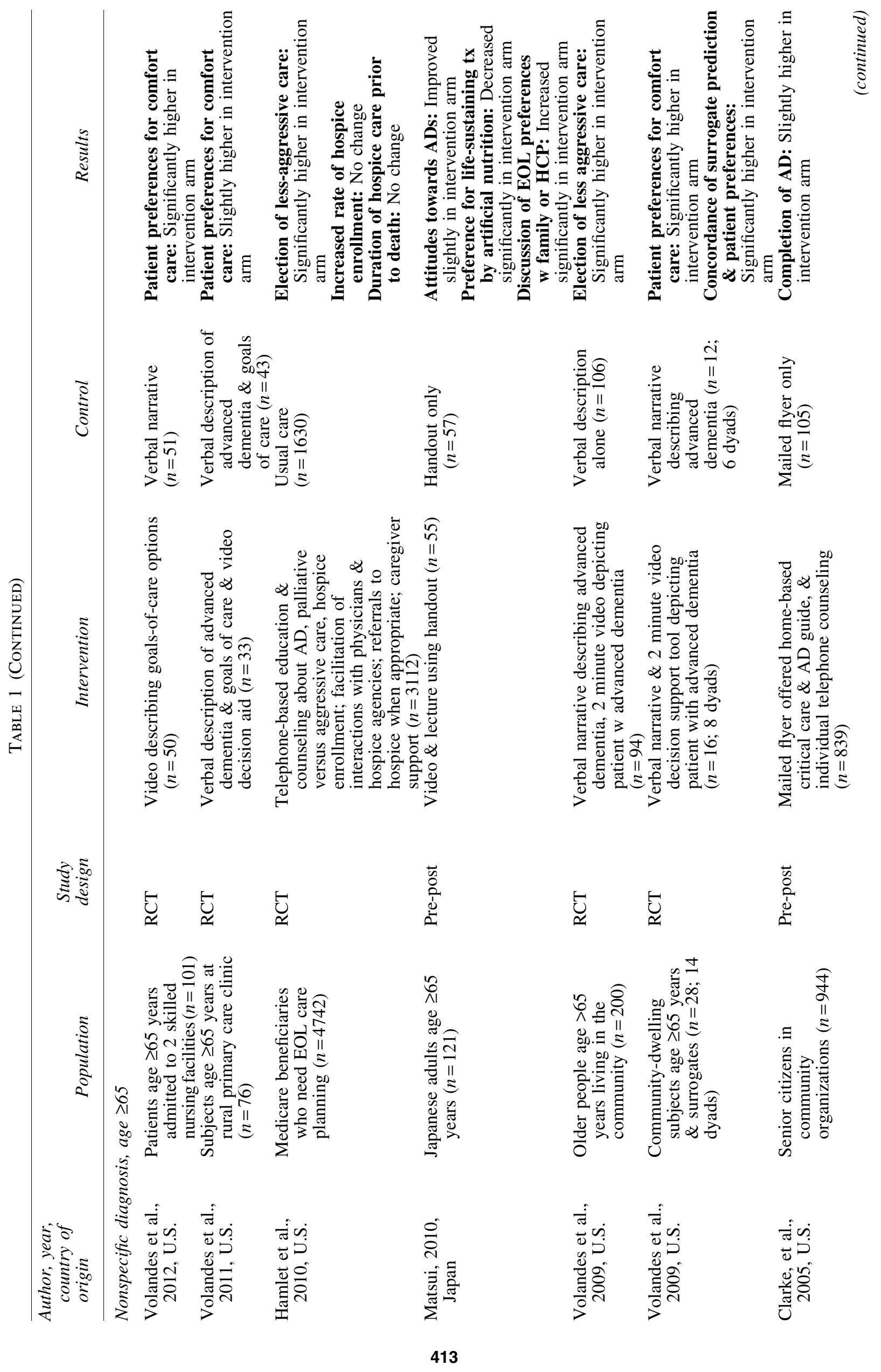




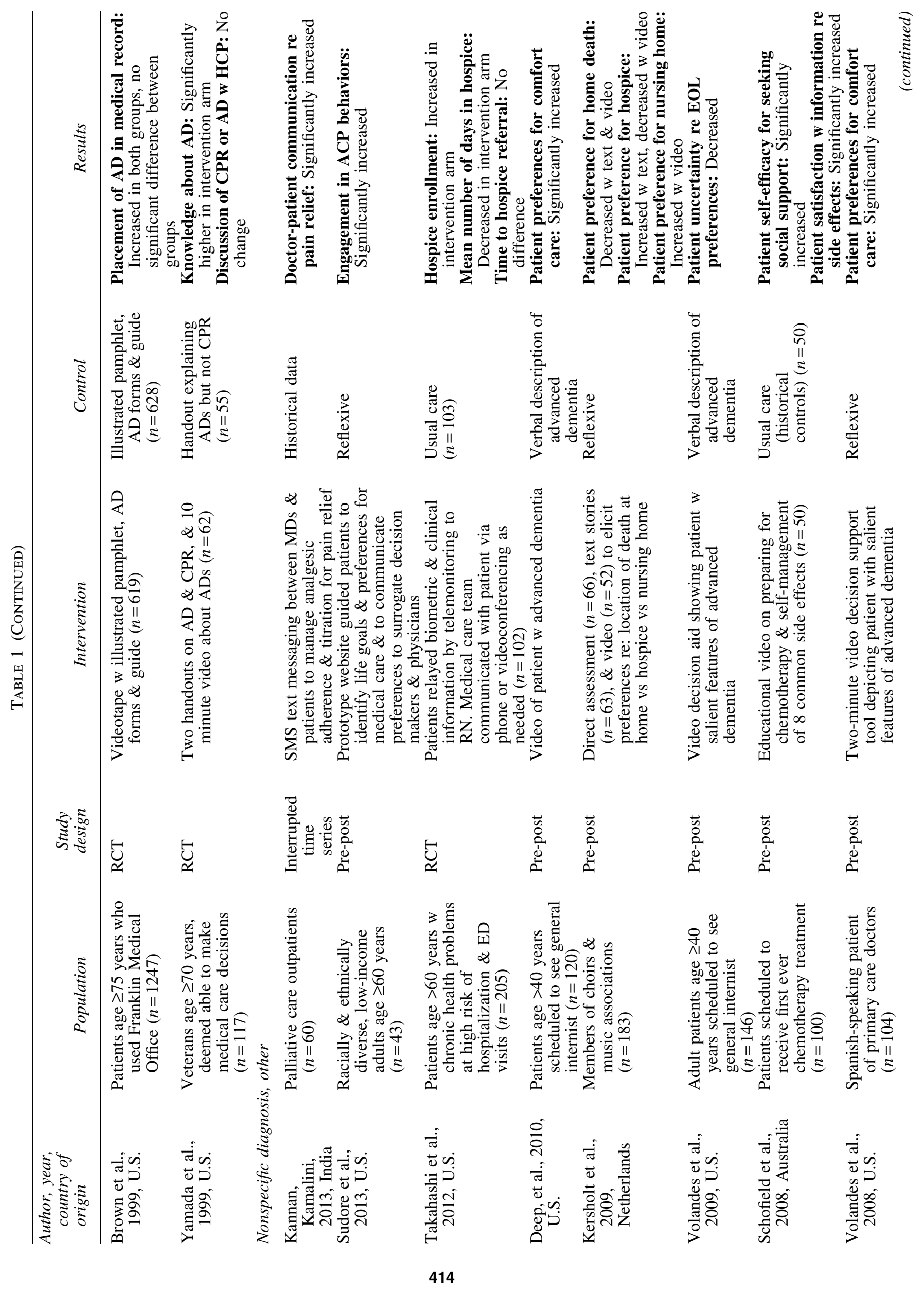




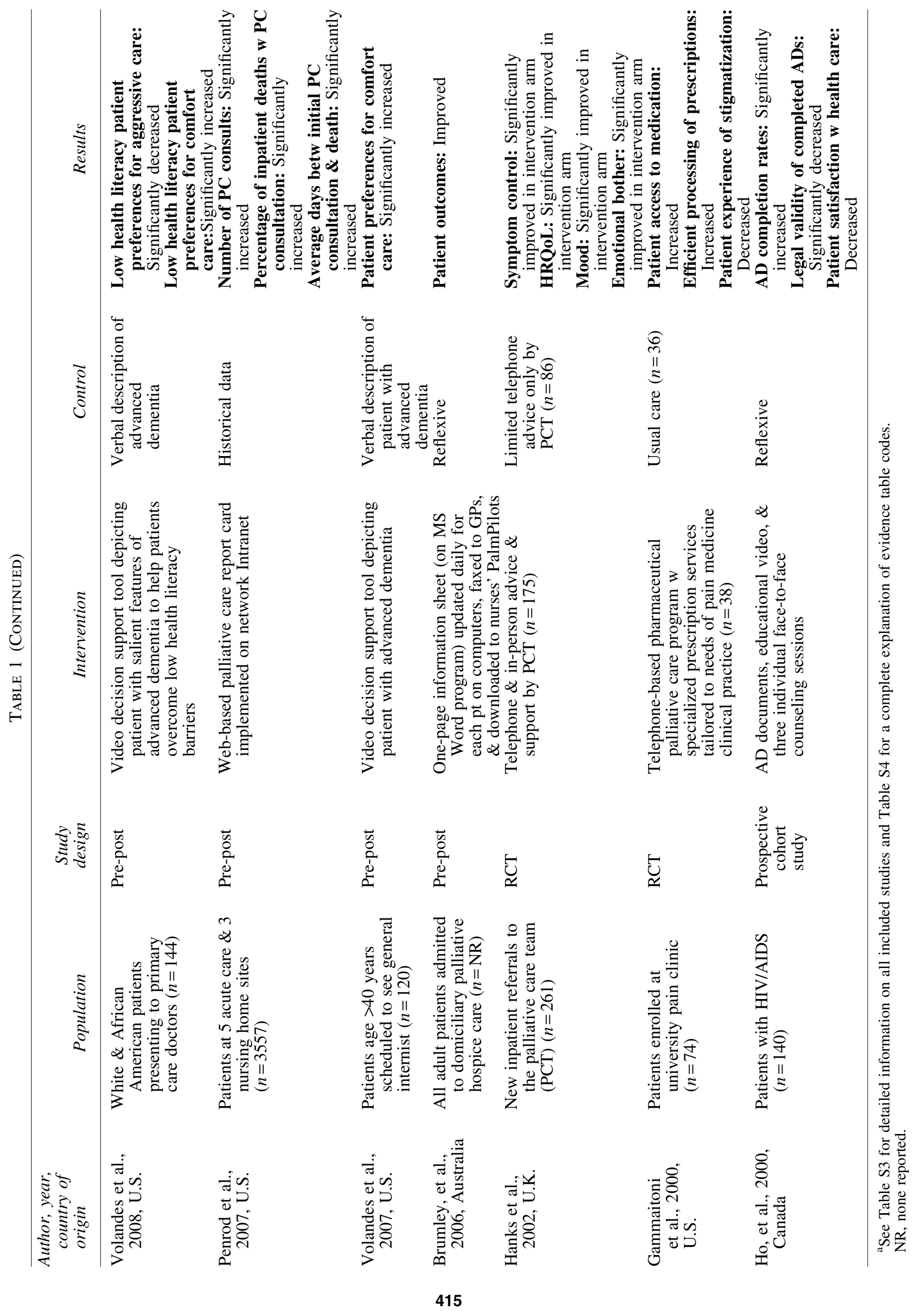




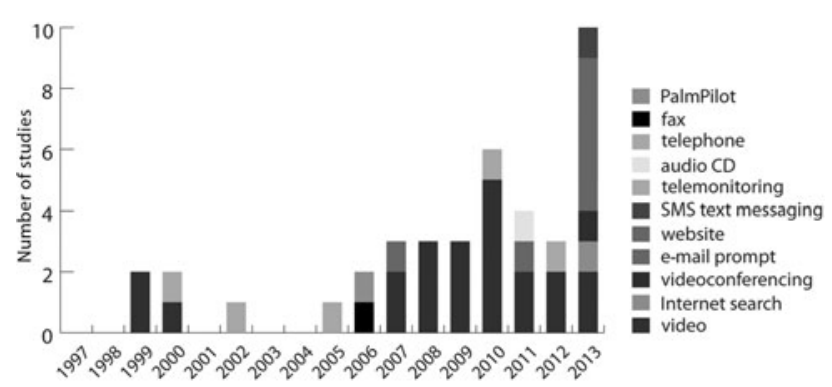

FIG. 2. Technology by date of study.

\section{Web-based interventions}

While the older technologies identified in this review, such as telephone and video, continue to be studied, the data indicate a trend toward increasing use of Internet-based interventions. Notably, four of the six studies in this review that developed prototype websites for health intervention were published in 2013. This shift is likely due to technological and infrastructure enhancements that have enabled access to high-speed broadband Internet across most of the United States, Canada, and western European countries. The recent studies using videoconferencing and e-mail prompts also reflect this shift toward delivering health interventions through networked ICTs. (See supplementary Table S5 for links to relevant web resources.) (See online supplementary Table S5 at www.liebertpub.com/jpm and at www.liebertonline .com.)

\section{Video}

With over half of the included studies $(n=22)$ using video as their intervention technology, the evidence base for the utility of this type of ICT in EOL communication is strong. In particular, numerous studies demonstrated the efficacy of video as a decision support tool in ACP. These results are not surprising, considering that the evidence base for video-based telehealth dates back to the 1950 s. $^{89,90}$ In addition, ICTs including video have been used for information/education and as decision aids in behavioral health interventions for other fields, where a variety of media technologies have been previously validated for these purposes. ${ }^{38,43-45,91,92}$ However, none of the video interventions employed mobile platforms to deliver the video, nor did they engage patients via popular video sites on the Internet. Interventions using video as a decision support tool in EOL care should begin to include mobile applications of video.

\section{Telemedicine}

None of the telephone-based studies included in this review used cellular phones or smartphones. However, the same principles concerning effects of face-to-face versus remote care would likely apply in both settings. Moreover, the evidence base for mHealth interventions using mobile phones for other health problems may provide valuable models for applications in EOL care. Evidence from related connected health fields such as remote ICU monitoring show promise and should guide future interventions in connected EOL care. $^{44,93}$

Several studies using new communication tools and techniques such as Skype, ${ }^{94}$ Twitter, ${ }^{95}$ and blogging ${ }^{96}$ were excluded on the basis of their study design, but suggest areas for further development of research to compare their effectiveness with analogous ICTs, such as hospital-based videoconferencing and e-mail. When possible, ICTs should be compared to one another, rather than solely to usual care.

\section{ICTs for cancer population}

Research on the use of ICTs in EOL care has developed most robustly among cancer researchers, with almost half the studies in this review focusing on cancer patients. It is possible that this emphasis is due to the better-known trajectory of certain types of terminal cancer, which may make the EOL stage of cancer more amenable to study than many other diseases. In addition, because cancer strikes across socioeconomic classes, it may be more feasible to pilot test new forms of health interventions that depend on ICT use enabled by

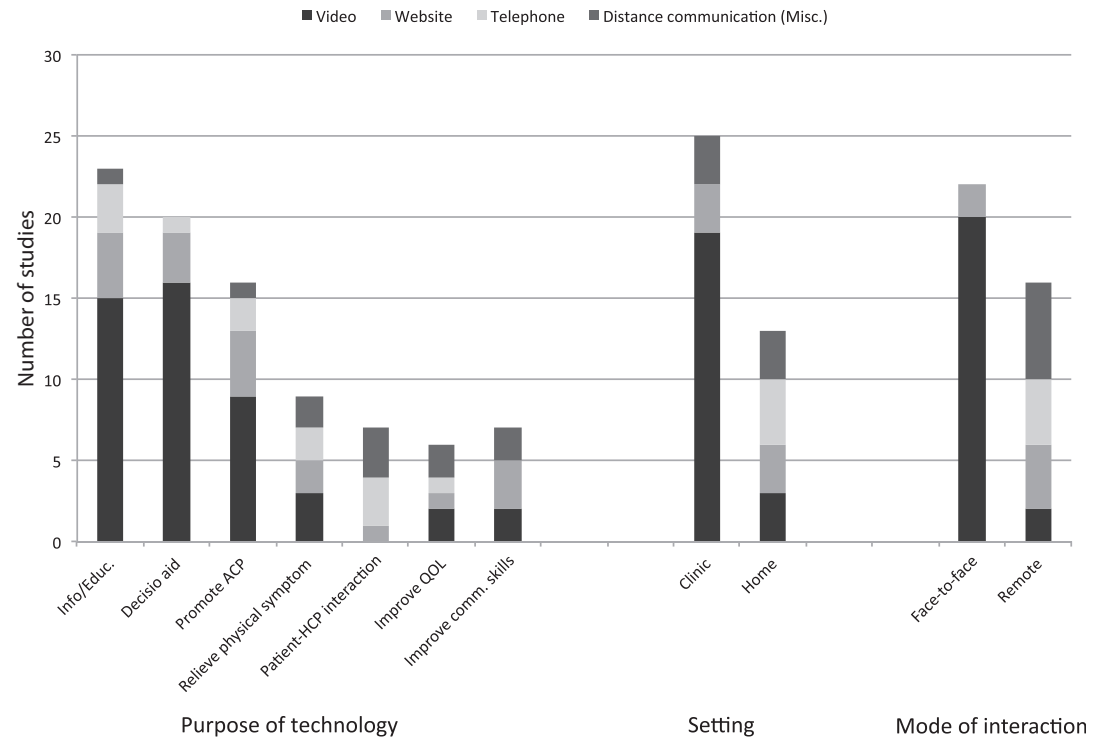

FIG. 3. Purpose of technology (by type of ICT). 
high-speed Internet connectivity and/or that depend on study subjects willing to engage with new technologies.

\section{Limitations}

A limitation of this review is the small sample size. Although the initial search captured over 2000 results, after applying the inclusion and exclusion criteria, the sample was reduced to only 38 studies. The widely heterogeneous results in this sample made comparison of effectiveness impossible; therefore the second objective of the study was not met. This review was limited to articles published in the English language, and therefore it may have missed significant research and trends taking place in other languages. In addition, the scope of this systematic review is broad, and the study covers diverse types of interventions. As a result, we were unable to calculate effect sizes. Finally, this review studies the use of ICTs in isolation from other dimensions of communication in patient care, both inside and outside of the health care setting. While the role of ICTs in EOL care shows significant promise, the use of technology will be but one among many different forms of communication that occur between the patient, family members, caregivers, and health care providers. The use of technologies in these settings will be best understood when studied in relation to other aspects of human communication.

\section{Conclusions}

Based on this systematic review of the literature on ICT use in EOL care, the authors have identified several opportunities for further research. First, future research should take advantage of the affordances of mobile, connected, health ICTs. Second, the proven value of video in helping patients clarify their treatment preferences should encourage more providers to experiment with this medium using mobile devices. Third, research is needed to help health care providers determine when face-to-face communication with patients is necessary, and when remote communication will achieve comparable objectives. If the results of such comparisons became generalizable, that would enable more rapid uptake of new technologies as they emerge.

Scalable innovations are sorely needed to improve quality of life at EOL while reducing the costs of care. ${ }^{97}$ Although emerging technologies are often associated with younger rather than older users, research shows that more and more aging Americans are using the Internet and connected health technologies, and this generational change will only increase as baby boomers grow old. ${ }^{3}$ As increasing numbers of Americans approach their final days with their laptops, smartphones, and tablets by their side, the use of ICTs to help them manage their health will become unavoidable. To ensure that mobile, networked ICTs are used effectively to optimize EOL care, it is essential that forward-looking research builds on the existing evidence base and continues to explore new techniques for delivering health care in the $21 \mathrm{st}$ century.

\section{Acknowledgments}

Research support was provided by Helena VonVille, MLS, Library Director, University of Texas School of Public
Health. Funding for this project was provided by a New Directions fellowship from the Andrew W. Mellon Foundation.

\section{Author Disclosure Statement}

No competing financial interests exist.

\section{References}

1. Colby SL, Ortman JM: The Baby Boom Cohort in the United States: 2012 to 2060: Population Estimates and Projections. U.S. Census Bureau, 2014.

2. Institute of Medicine: Dying in America: Improving Quality and Honoring Individual Preferences Near the End of Life. National Academies Press, 2015.

3. Smith A: Older Adults and Technology Use. Pew Research Center, 2014.

4. Baker C, Seegert L: A Platform for Aging in Place: The Increasing Potential of High-Speed Internet Connectivity. AARP Public Policy Institute, 2013.

5. Lake Research Partners; Coalition for Compassionate Care of California: Final Chapter: Californians' Attitudes and Experiences with Death and Dying. California HealthCare Foundation, 2012.

6. Ventura AD, Burney S, Brooker J, et al.: Home-based palliative care: A systematic literature review of the selfreported unmet needs of patients and carers. Palliat Med 2014;28:391-402.

7. Institute of Medicine: Approaching Death: Improving Care at the End of Life. Institute of Medicine, 1997.

8. Barclay S, Maher J: Having the difficult conversations about the end of life. BMJ 2010;341:c4862.

9. Quill TE: Perspectives on care at the close of life: Initiating end-of-life discussions with seriously ill patients: Addressing the "elephant in the room." JAMA 2000;284:2502-2507.

10. Christakis NA, Lamont EB: Extent and determinants of error in doctors' prognoses in terminally ill patients: Prospective cohort study. BMJ 2000;320:469-472.

11. Christakis NA, Iwashyna TJ: Attitude and self-reported practice regarding prognostication in a national sample of internists. Arch Intern Med 1998;158:2389-2395.

12. Wright AA, Zhang B, Ray A, et al.: Associations between end-of-life discussions, patient mental health, medical care near death, and caregiver bereavement adjustment. JAMA 2008;300:1665-1673.

13. Mack JW, Weeks JC, Wright AA, et al.: End-of-life discussions, goal attainment, and distress at the end of life: Predictors and outcomes of receipt of care consistent with preferences. J Clin Oncol 2010;28:1203-1208.

14. Zhang B, Wright AA, Huskamp HA, et al.: Health care costs in the last week of life: Associations with end-of-life conversations. Arch Intern Med 2009;169:480-488.

15. Goodman D, Morden N, Chang $\mathrm{CH}$, et al.: Trends in Cancer Care Near the End of Life: A Dartmouth Atlas of Health Care Brief. The Dartmouth Institute for Health Policy \& Clinical Practice, 2013.

16. Riley GF, Lubitz JD: Long-term trends in Medicare payments in the last year of life. Health Serv Res 2010;45:565-576.

17. Hoover DR, Crystal S, Kumar R, et al.: Medical expenditures during the last year of life: Findings from the 19921996 Medicare current beneficiary survey. Health Serv Res 2002;37:1625-1642.

18. Prigerson HG, Maciejewski PK: Dartmouth Atlas: Putting end-of-life care on the map but missing psychosocial detail. J Support Oncol 2012;10:25-28. 
19. Earle CC, Neville BA, Landrum MB, et al.: Trends in the aggressiveness of cancer care near the end of life. J Clin Oncol 2004;22:315-321.

20. Earle CC, Landrum MB, Souza JM, et al.: Aggressiveness of cancer care near the end of life: Is it a quality-of-care issue? J Clin Oncol 2008;26:3860-3866.

21. Emanuel EJ, Young-Xu Y, Levinsky NG, et al.: Chemotherapy use among Medicare beneficiaries at the end of life. Ann Intern Med 2003;138:639-643.

22. Temel JS, McCannon J, Greer JA, et al.: Aggressiveness of care in a prospective cohort of patients with advanced NSCLC. Cancer 2008;113:826-833.

23. Teno JM, Fisher ES, Hamel MB, et al.: Medical care inconsistent with patients' treatment goals: Association with 1-year Medicare resource use and survival. J Am Geriatr Soc 2002;50:496-500.

24. Kelley AS, Deb P, Du Q, et al.: Hospice enrollment saves money for Medicare and improves care quality across a number of different lengths-of-stay. Health Aff (Millwood) 2013;32:552-561.

25. Bisognano M, Goodman E: Engaging patients and their loved ones in the ultimate conversation. Health Aff (Millwood) 2013;32:203-206.

26. Teno JM, Licks S, Lynn J, et al.: Do advance directives provide instructions that direct care? SUPPORT Investigators. Study to Understand Prognoses and Preferences for Outcomes and Risks of Treatment. J Am Geriatr Soc 1997;45:508-512.

27. Virmani J, Schneiderman LJ, Kaplan RM: Relationship of advance directives to physician-patient communication. Arch Intern Med 1994;154:909-913.

28. Hammes BJ, Rooney BL, Gundrum JD, et al.: The POLST program: A retrospective review of the demographics of use and outcomes in one community where advance directives are prevalent. J Palliat Med 2012;15:77-85.

29. Olszewski EA, Newgard CD, Zive D, et al.: Validation of physician orders for life-sustaining treatment: Electronic registry to guide emergency care. J Am Geriatr Soc 2012;60: 1384-1386.

30. Fromme EK, Zive D, Schmidt TA, et al.: POLST registry do-not-resuscitate orders and other patient treatment preferences. JAMA 2012;307:34-35.

31. Klugman CM, Usatine RP: An evaluation of 2 online advance directive programs. Am J Hosp Palliat Care 2013;30: 657-663.

32. Bruera E, Yennurajalingam S, Palmer JL, et al.: Methylphenidate and/or a nursing telephone intervention for fatigue in patients with advanced cancer: A randomized, placebocontrolled, phase II trial. J Clin Oncol 2013;31:2421-2427.

33. Volandes AE, Brandeis GH, Davis AD, et al.: A randomized controlled trial of a goals-of-care video for elderly patients admitted to skilled nursing facilities. J Palliat Med 2012;15:805-811.

34. Volandes AE, Levin TT, Slovin S, et al.: Augmenting advance care planning in poor prognosis cancer with a video decision aid: A preintervention-postintervention study. Cancer 2012;118:4331-4338.

35. Eysenbach G: What is e-health? J Med Internet Res 2001; 3:E20.

36. European Institute of Public Administration: The case for ehealth. European Institute of Public Administration, 2003.

37. Kreuter M, Farrell D, Brennan L: Tailoring Health Messages: Customizing Communication with Computer Technology. Mahwah, NJ: Lawrence Erlbaum, 2000.
38. Rimer B, Kreuter M: Advancing tailored health communication: A persuasion and message effects perspective. $\mathbf{J}$ Commun 2006;56:S184-S201.

39. Wright K, Sparks L, O'Hair D: Health Communication in the 21st Century, 2nd ed. Malden, MA: Wiley-Blackwell, 2013.

40. Manne S, Jacobsen PB, Ming ME, et al.: Tailored versus generic interventions for skin cancer risk reduction for family members of melanoma patients. Health Psychol 2010;29:583-593.

41. Resnicow K, Davis R, Zhang N, et al.: Tailoring a fruit and vegetable intervention on ethnic identity: Results of a randomized study. Health Psychol 2009;28:394-403.

42. Montague E, Perchonok J: Health and wellness technology use by historically underserved health consumers: Systematic review. J Med Internet Res 2012;14:e78.

43. Shegog R, Bamps YA, Patel A, et al.: Managing epilepsy well: Emerging e-tools for epilepsy self-management. Epilepsy Behav 2013;29:133-140.

44. Kvedar J, Coye MJ, Everett W: Connected health: A review of technologies and strategies to improve patient care with telemedicine and telehealth. Health Aff (Millwood) 2014;33:194-199.

45. Allison S, Bauermeister J, Bull S, et al.: The intersection of youth, technology, and new media with sexual health: Moving the research agenda forward. J Adolesc Health 2012;51:207-212.

46. Koh HK, Berwick DM, Clancy CM, et al.: New federal policy initiatives to boost health literacy can help the nation move beyond the cycle of costly 'crisis care'. Health Aff (Millwood) 2012;31:434-443.

47. The American Recovery and Reinvestment Act of 2009, Pub.L. 111-5, 123 Stat. 115 (2009).

48. Capurro D, Ganzinger M, Perez-Lu J, Knaup P: Effectiveness of eHealth interventions and information needs in palliative care: A systematic literature review. J Med Internet Res 2014;16:e72.

49. Parker SM, Clayton JM, Hancock K, et al.: A systematic review of prognostic/end-of-life communication with adults in the advanced stages of a life-limiting illness: Patient/ caregiver preferences for the content, style, and timing of information. J Pain Symptom Manage 2007;34:81-93.

50. Houttekier D, Cohen J, Cools F, Deliens L: Advance care planning for end-of-life care (Protocol). Cochrane Lib 2012.

51. Moher D, Liberati A, Tetzlaff J, Altman D: Preferred Reporting Items for Systematic Reviews and Meta-Analyses: The PRISMA Statement. Ann Intern Med 2009;151.

52. Higgins J, Green S (eds): Cochrane Handbook for Systematic Reviews of Interventions. 5.1.0 ed. The Cochrane Collaboration, 2011.

53. Uitdehaag MJ, van der Velden LA, de Boer MF, et al.: Recordings of consultations are beneficial in the transition from curative to palliative cancer care: A pilot-study in patients with oesophageal or head and neck cancer. Eur J Oncol Nurs 2012;16:109-114.

54. Yun YH, Lee MK, Park S, et al.: Use of a decision aid to help caregivers discuss terminal disease status with a family member with cancer: A randomized controlled trial. J Clin Oncol 2011;29:4811-4819.

55. Hamlet KS, Hobgood A, Hamar GB, et al:: Impact of predictive model-directed end-of-life counseling for Medicare beneficiaries. Am J Manag Care 2010;16:379-384.

56. Volandes AE, Paasche-Orlow MK, Barry MJ, et al.: Video decision support tool for advance care planning in dementia: Randomised controlled trial. BMJ 2009;338:b2159. 
57. Hanks GW, Robbins M, Sharp D, et al.: The imPaCT study: A randomised controlled trial to evaluate a hospital palliative care team. Br J Cancer 2002;87:733-739.

58. Vogel RI, Petzel SV, Cragg J, et al.: Development and pilot of an advance care planning website for women with ovarian cancer: A randomized controlled trial. Gynecol Oncol 2013;131:430-436.

59. Epstein AS, Volandes AE, Chen LY, et al.: A randomized controlled trial of a cardiopulmonary resuscitation video in advance care planning for progressive pancreas and hepatobiliary cancer patients. J Palliat Med 2013;16:623-631.

60. Gustafson DH, DuBenske LL, Namkoong K, et al.: An eHealth system supporting palliative care for patients with non-small cell lung cancer: A randomized trial. Cancer 2013;119:1744-1751.

61. Temel JS, Greer JA, Gallagher ER, et al.: Electronic prompt to improve outpatient code status documentation for patients with advanced lung cancer. J Clin Oncol 2013; 31:710-715.

62. Volandes AE, Paasche-Orlow MK, Mitchell SL, et al.: Randomized controlled trial of a video decision support tool for cardiopulmonary resuscitation decision making in advanced cancer. J Clin Oncol 2013;31:380-386.

63. Takahashi PY, Hanson GJ, Thorsteinsdottir B, et al.: The impact of telemonitoring upon hospice referral in the community: A randomized controlled trial. Clin Interv Aging 2012;7:445-451.

64. Volandes AE, Ferguson LA, Davis AD, et al.: Assessing end-of-life preferences for advanced dementia in rural patients using an educational video: A randomized controlled trial. J Palliat Med 2011;14:169-177.

65. El-Jawahri A, Podgurski LM, Eichler AF, et al.: Use of video to facilitate end-of-life discussions with patients with cancer: A randomized controlled trial. J Clin Oncol 2010; 28:305-310.

66. Volandes AE, Mitchell SL, Gillick MR, et al.: Using video images to improve the accuracy of surrogate decision-making: A randomized controlled trial. J Am Med Dir Assoc 2009; 10:575-580.

67. Penrod JD, Cortez T, Luhrs CA: Use of a report card to implement a network-based palliative care program. J Palliat Med 2007;10:858-860.

68. Clarke P, Evans SH, Shook D, Johanson W: Information seeking and compliance in planning for critical care: Community-based health outreach to seniors about advance directives. Health Commun 2005;18:1-22.

69. Green MJ, Levi BH: Teaching advance care planning to medical students with a computer-based decision aid. J Cancer Educ 2011;26:82-91.

70. Deep KS, Hunter A, Murphy K, Volandes A: “It helps me see with my heart:" How video informs patients' rationale for decisions about future care in advanced dementia. Patient Educ Couns 2010;81:229-234.

71. Volandes AE, Ariza M, Abbo ED, Paasche-Orlow M: Overcoming educational barriers for advance care planning in Latinos with video images. J Palliat Med 2008;11:700-706.

72. Yamada R, Galecki AT, Goold SD, Hogikyan RV: A multimedia intervention on cardiopulmonary resuscitation and advance directives. J Gen Intern Med 1999;14:559-563.

73. Pelayo-Alvarez M, Perez-Hoyos S, Agra-Varela Y: Clinical effectiveness of online training in palliative care of primary care physicians. J Palliat Med 2013;16:1188-1196.

74. Kannan R, Kamalini S: A novel and cost-effective way to follow-up adequacy of pain relief, adverse effects, and compliance with analgesics in a palliative care clinic. Indian J Palliat Care 2013;19:54-57.

75. Kerstholt JH, Van Der Zwaard F, Bart H, Cremers A: Construction of health preferences: A comparison of direct value assessment and personal narratives. Med Decis Making 2009;29:513-520.

76. Gammaitoni AR, Gallagher RM, Welz M, et al.: Palliative pharmaceutical care: A randomized, prospective study of telephone-based prescription and medication counseling services for treating chronic pain. Pain Med 2000;1:317-331.

77. Ho VW, Thiel EC, Rubin HR, Singer PA: The effect of advance care planning on completion of advance directives and patient satisfaction in people with HIV/AIDS. AIDS Care 2000;12:97-108.

78. Sudore RL, Knight SJ, McMahan RD, et al.: A novel website to prepare diverse older adults for decision making and advance care planning: A pilot study. J Pain Symptom Manage 2014;47:674-686.

79. Brown JB, Beck A, Boles M, Barrett P: Practical methods to increase use of advance medical directives. J Gen Intern Med 1999;14:21-26.

80. Capewell C, Gregory W, Closs S, Bennett M: Brief DVDbased educational intervention for patients with cancer pain: Feasibility study. Palliat Med 2010;24:616-622.

81. Matsui M: Effectiveness of end-of-life education among community-dwelling older adults. Nurs Ethics 2010;17: 363-372.

82. Volandes AE, Barry MJ, Chang Y, Paasche-Orlow MK: Improving decision making at the end of life with video images. Med Decis Making 2010;30:29-34.

83. Volandes AE, Lehmann LS, Cook EF, et al.: Using video images of dementia in advance care planning. Arch Intern Med 2007;167:828-833.

84. Duggleby WD, Degner L, Williams A, et al.: Living with hope: Initial evaluation of a psychosocial hope intervention for older palliative home care patients. J Pain Symptom Manage 2007;33:247-257.

85. Watanabe SM, Fairchild A, Pituskin E, et al.: Improving access to specialist multidisciplinary palliative care consultation for rural cancer patients by videoconferencing: Report of a pilot project. Support Care Cancer 2013;21:1201-1207.

86. Volandes AE, Paasche-Orlow M, Gillick MR, et al.: Health literacy not race predicts end-of-life care preferences. J Palliat Med 2008;11:754-762.

87. Schofield P, Jefford M, Carey M, et al.: Preparing patients for threatening medical treatments: Effects of a chemotherapy educational DVD on anxiety, unmet needs, and self-efficacy. Support Care Cancer 2008;16:37-45.

88. Brumley D, Fisher J, Robinson H, Ashby M: Improving access to clinical information in after hours community palliative care. Aust J Adv Nurs 2006;24:27-32.

89. Ostherr K: Medical Visions: Producing the Patient through Film, Television, and Imaging Technologies. New York: Oxford University Press, 2013.

90. Serlin D: Performing live surgery on television and the internet since 1945. In: Serlin D (ed): Imagining Illness: Public Health and Visual Culture. Minneapolis, MN: University of Minnesota Press, 2010, pp. 223-244.

91. Ostherr K: Cinematic Prophylaxis: Globalization and Contagion in the Discourse of World Health. Durham, NC: Duke University Press, 2005.

92. Fuqua J: Prescription TV: Therapeutic Discourse in the Hospital and at Home. Durham, NC: Duke University Press, 2012. 
93. Cortez NG, Cohen IG, Kesselheim AS: FDA regulation of mobile health technologies. N Engl J Med 2014;371:372379.

94. Brecher DB: The use of Skype in a community hospital inpatient palliative medicine consultation service. J Palliat Med 2013;16:110-112.

95. Nicholson C: Palliative care on Twitter: Who to follow to get started. Int J Palliat Nurs 2013;19:6-7.

96. Lowney AC, O'Brien T: The landscape of blogging in palliative care. Palliat Med 2012;26:858-859.
97. Berwick D, Nolan T, Whittington J: The triple aim: Care, health, and cost. Health Aff 2008;27:759-769.

Address correspondence to: Kirsten Ostherr, PhD, MPH

Rice University

6100 Main Street, MS-30

Houston, TX 77005

E-mail: kostherr@rice.edu 